\title{
Turbinaria sp. as victims to Kappaphycus alvarezii in reefs of Gulf of Mannar, India
}

Received: 12 July 2010/ Accepted: 20 August 2010/Published online: 16 October 2010

(C) Springer-Verlag 2010

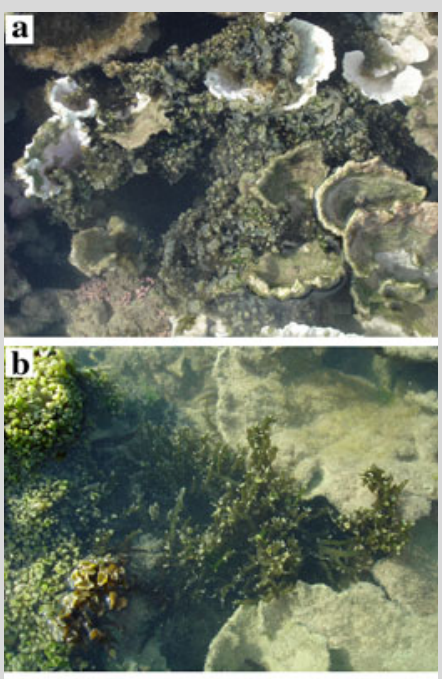

The Gulf of Mannar (GoM), India, includes 21 coral islands $\left(8^{\circ} \mathrm{N} ; 79^{\circ} \mathrm{E}\right)$, covers an area of 10,500 sq. km and supports 94 species of corals belonging to 37 genera. Kappaphycus alvarezii, a Philippine-derived rhodophyte, has been introduced into the GoM for commercial cultivation in 2002. The ecological threat from this invasive alga to coral species in GoM was first indicated by Pereira and Verlecar (2005). After 6 years of its introduction, its bioinvasion on branching corals (Acropora species) in the Kurusadai island $\left(9^{\circ} 15^{\prime} \mathrm{N} ; 79^{\circ} 12^{\prime} \mathrm{E}\right)$ of GoM was reported in 2008 (Chandrasekaran et al. 2008). Consequently, commercial cultivation of this invasive alga was prohibited. A mechanical removal programme started in 2009 by the State Government at the invaded site could not deliver expected results. Thus, this alga enjoys a freedom of unrestricted spread and aggressive growth in GoM, predominantly on species of Acropora. On 28 April 2010, during our routine sampling visit at Kurusadai Island, unusual appearance of $K$. alvarezii, on the cup coral, Turbinaria sp. was observed (Fig. 1a). The space between the plates of Turbinaria sp. provides an ideal settlement surface for $K$. alvarezii, which protect them from the wave action and favour the profuse growth of secondary branches of $K$. alvarezii between the plates (Fig. 1b) in contrast to the smothering effect on the top of coral plates (Fig. 1c). This finding shows that $K$. alvarezii is capable of invading species of nonbranching corals as reported in Hawaii for Montipora capitata and Porites compressa (Conklin and Smith 2005). Therefore, perhaps this is the first report from India on

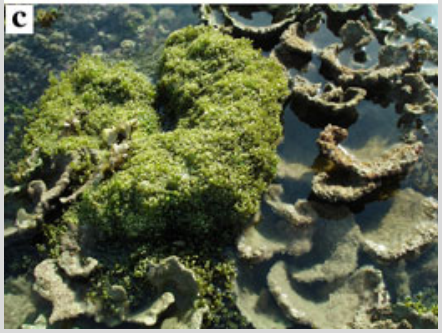
bioinvasion of $K$. alvarezii on a non-branching coral (Turbinaria sp.) in the GoM.

Acknowledgments We thank CSIR and UGC, Government of India, New Delhi, for financial assistance and Department of Forestry, Government of Tamil Nadu for encouragement. We are thankful to the topic editor and three anonymous reviewers for their suggestions and comments.

\section{References}

Fig. 1 a Kappaphycus alvarezii on Turbinaria sp. at Kurusadai island, Gulf of Mannar, b Profuse growth of K. alvarezii between the plates of Turbinaria sp. and c Smothering effect of $K$. alvarezii on the top of the Turbinaria sp

Chandrasekaran S, Nagendran NA, Pandiaraja D, Krishnankutty N, Kamalakannan B (2008) Bioinvasion of Kappaphycus alvarezii on corals in the Gulf of Mannar, India. Curr Sci 94:1167-1172

Conklin EJ, Smith JE (2005) Abundance and spread of the invasive red algae Kappaphycus spp. in Kaneohe Bay, Hawaii and an experimental assessment of management options. Biol Invasion 7:1029-1032

Pereira N, Verlecar XN (2005) Is Gulf of Mannar heading for marine bioinvasion? Curr Sci 89:1309-1310

B. Kamalakannan · J. J. J. Jeevamani · N. A. Nagendran · D. Pandiaraja

Thiagarajar College, Madurai 625009, India

N. Krishnan Kutty

$1 / 2$ E2 E2 Road, Chinnachokikulam, Madurai 625002, India

S. Chandrasekaran $(\bowtie)$

Department of Bio-Energy, Madurai Kamaraj University, Madurai 625021, India

e-mail: krishnanasc@yahoo.co.in

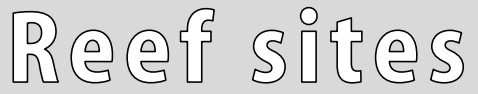

Coral Reefs (2010) 29:1077

DOI $10.1007 / \mathrm{s} 00338-010-0684-4$ 